\title{
Calpain modulates capacitation and acrosome reaction through cleavage of the spectrin cytoskeleton
}

\author{
Yadira Bastián, Ana L Roa-Espitia ${ }^{1}$, Adela Mújica ${ }^{1}$ and Enrique O Hernández-González ${ }^{1}$ \\ Deparment of Biology, McGill University, Montreal, Quebec, Canada H3A 1 B1 and ${ }^{1}$ Departamento de Biología \\ Celular, Centro de Investigación y Estudios Avanzados del Instituto Politécnico Nacional, Avenue IPN 2508, San Pedro \\ Zacatenco, México DF 07360, Mexico
}

Correspondence should be addressed to E O Hernández-González; Email: eoton@cell.cinvestav.mx

Y Bastián and A L Roa-Espitia contributed equally to this work

\begin{abstract}
Research on fertilization in mammalian species has revealed that $\mathrm{Ca}^{2+}$ is an important player in biochemical and physiological events enabling the sperm to penetrate the oocyte. $\mathrm{Ca}^{2+}$ is a signal transducer that particularly mediates capacitation and acrosome reaction (AR). Before becoming fertilization competent, sperm must experience several molecular, biochemical, and physiological changes where $\mathrm{Ca}^{2+}$ plays a pivotal role. Calpain-1 and calpain-2 are $\mathrm{Ca}^{2+}$-dependent proteases widely studied in mammalian sperm; they have been involved in capacitation and AR but little is known about their mechanism. In this work, we establish the association of calpastatin with calpain-1 and the changes undergone by this complex during capacitation in guinea pig sperm. We found that calpain-1 is relocated and translocated from cytoplasm to plasma membrane (PM) during capacitation, where it could cleave spectrin, one of the proteins of the PM-associated cytoskeleton, and facilitates AR. The aforementioned results were dependent on the calpastatin phosphorylation and the presence of extracellular $\mathrm{Ca}^{2+}$. Our findings underline the contribution of the sperm cytoskeleton in the regulation of both capacitation and AR. In addition, our findings also reveal one of the mechanisms by which calpain and calcium exert its function in sperm.
\end{abstract}

Reproduction (2010) $\mathbf{1 4 0}$ 673-684

\section{Introduction}

Freshly ejaculated mammalian sperm are unable to fertilize mature oocytes; in order to become fertilization competent, they must go through a process called capacitation. Capacitation occurs in vivo in the female reproductive tract, but can be mimicked in vitro by incubation in specially defined media. Capacitation involves reorganization of the plasma membrane (PM), an increase in protein tyrosine phosphorylation, and hyperpolarization of the PM potential (Em). During capacitation, there is an increase in the intracellular concentration of $\mathrm{Ca}^{2+}, \mathrm{cAMP}$, and $\mathrm{pH}$ (Salicioni et al. 2007, Abou-haila \& Tulsiani 2009). Capacitation is also associated with the appearance of hyperactivated motility (Salicioni et al. 2007, Suarez 2008). Once capacitation is completed, sperm are able to undergo the acrosome reaction (AR), an exocytotic process induced by ZP3, a component of the zona pellucida. AR allows the sperm to penetrate the zona pellucida and to fuse with the egg's PM. Both capacitation and $\mathrm{AR}$ absolutely require $\mathrm{Ca}^{2+}$ influx to activate several indispensable signal pathways (Darszon et al. 2005, Publicover et al. 2007).
Calpains belong to a family of non-lysosomal $\mathrm{Ca}^{2+}$-dependent cysteine proteases widely expressed in a variety of tissues and cells (Molinari \& Carafoli 1997, Goll et al. 2003). The most ubiquitous and very wellcharacterized isoforms are calpain-1 and calpain-2. Because the activation of their $80 \mathrm{kDa}$ large catalytic subunit differs in $\mathrm{Ca}^{2+}$ concentration requirements, calpain-1, which is activated at the micromolar range, is also known as $\mu$-calpain, whereas calpain-2, which is activated at the millimolar range, is also called m-calpain (Croall \& DeMartino 1991, Goll et al. 2003). Calpain is involved in cytoskeleton remodeling, cell adhesion and motility, cell cycle regulation, as well as in cell differentiation and apoptosis (Croall \& DeMartino 1991, Lebart \& Benyamin 2006). The activity of calpain is tightly regulated by several mechanisms, including its endogenous inhibitor calpastatin, calcium levels, autoproteolytic cleavage, and phosphorylation (Molinari \& Carafoli 1997, Goll et al. 2003, Franco \& Huttenlocher 2005). Calpain plays an important role in the turnover of different molecules related to cell adhesion and motility by the cleavage of many adhesion and cytoskeletal proteins, such as spectrin (Franco \& Huttenlocher 2005, Lebart \& Benyamin 2006). 
In mammalian sperm, calpain-1 and calpain-2 are located within the acrosomal region (Schollmeyer 1986, Ben-Aharon et al. 2005) between the PM and the outer acrosomal membrane (Yudin et al. 2000). Interestingly, it has been shown that sperm capacitation in the presence of calpain inhibitors results in a reduction of AR (Rojas et al. 1999, Aoyama et al. 2001, Ben-Aharon et al. 2005); however, the role of calpain during capacitation or AR remains unclear.

The surface of mammalian sperm displays diverse membrane domains with distinct biochemical and functional characteristics; these domains are very important for capacitation, AR, and motility (Forsman \& Pinto da Silva 1989). Diverse cytoskeletal proteins have been found to be associated with these membrane domains, for instance F-actin (Castellani-Ceresa et al. 1992, Moreno-Fierros et al. 1992, Kann et al. 1993, Spungin et al. 1995, Yagi \& Paranko 1995), spectrin (Virtanen et al. 1984, Camatini et al. 1991, HernandezGonzalez et al. 2000), as well as dystrophin and utrophin (Hernandez-Gonzalez et al. 2001, 2005). Interestingly, because F-actin and spectrin form a network associated with the plasma and outer acrosomal membranes (Hernandez-Gonzalez et al. 2000) that may act as a physical barrier preventing membrane fusion (Spungin et al. 1995, Hernandez-Gonzalez et al. 2000), remodeling of the cortical actin cytoskeleton could facilitate capacitation and AR (Brener et al. 2003, Cabello-Agueros et al. 2003). Several lines of evidence support this hypothesis as follows: 1) F-actin polymerization/depolymerization processes have been observed during capacitation and AR (Spungin et al. 1995, Hernandez-Gonzalez et al. 2000), 2) phalloidininduced F-actin stabilization blocks membrane fusion and AR (Spungin et al. 1995, Hernandez-Gonzalez et al. 2000), and 3) F-actin severing proteins like gelsolin and scinderin have been found within the acrosomal region of mammalian sperm (Pelletier et al. 1999, CabelloAgueros et al. 2003). Moreover, spectrin actively participates in the assembly of specialized membrane domains in addition to their conventional maintenance role as scaffolding protein for ion channels and transporters as well as for cell adhesion molecules (Bennett \& Healy 2008). Spectrin is associated with the cytoplasmic surface of the sperm PM in the acrosomal region and in the flagella (Camatini et al. 1991, Hernandez-Gonzalez et al. 2000), although its function in mammalian sperm is unknown.

Since the exact function of calpain in sperm physiology remains unclear, the present study was conducted to 1) evaluate the presence of calpain-1 and calpain-2 as well as its natural regulator calpastatin in guinea pig sperm, 2) distinguish if calpain is activated during capacitation, and 3) to determine the participation of calpain in cytoskeleton remodeling during capacitation.

\section{Results Calpain-1 and calpastatin are expressed in guinea pig
spermatozoa}

Consistent with the molecular weight reported for mouse, human, and macaque sperm (Rojas et al. 1999, Yudin et al. 2000, Ben-Aharon et al. 2005), the anticalpain-1 antibody detected a $80 \mathrm{kDa}$ protein, whereas the anti-calpastatin antibody detected a band of $70 \mathrm{kDa}$ (Fig. $1 \mathrm{~A}$ and $\mathrm{B}$ ). The bands we detected were also present in erythrocytes and Jurkat cells, which were used here as positive controls (Sasaki et al. 1983, Murakami et al. 1988, Porn-Ares et al. 1998). Using the same antibodies, we next determined the localization of calpain- 1 and calpastatin by indirect immunofluorescence; both calpain-1 and calpastatin were detected in the whole acrosomal region and in the middle piece of noncapacitated sperm (Fig. 1C). Because calpain-2 has been reported in pig, human, macaque, and mouse sperm (Schollmeyer 1986, Rojas et al. 1999, Yudin et al. 2000, Ben-Aharon et al. 2005), we then sought for its presence
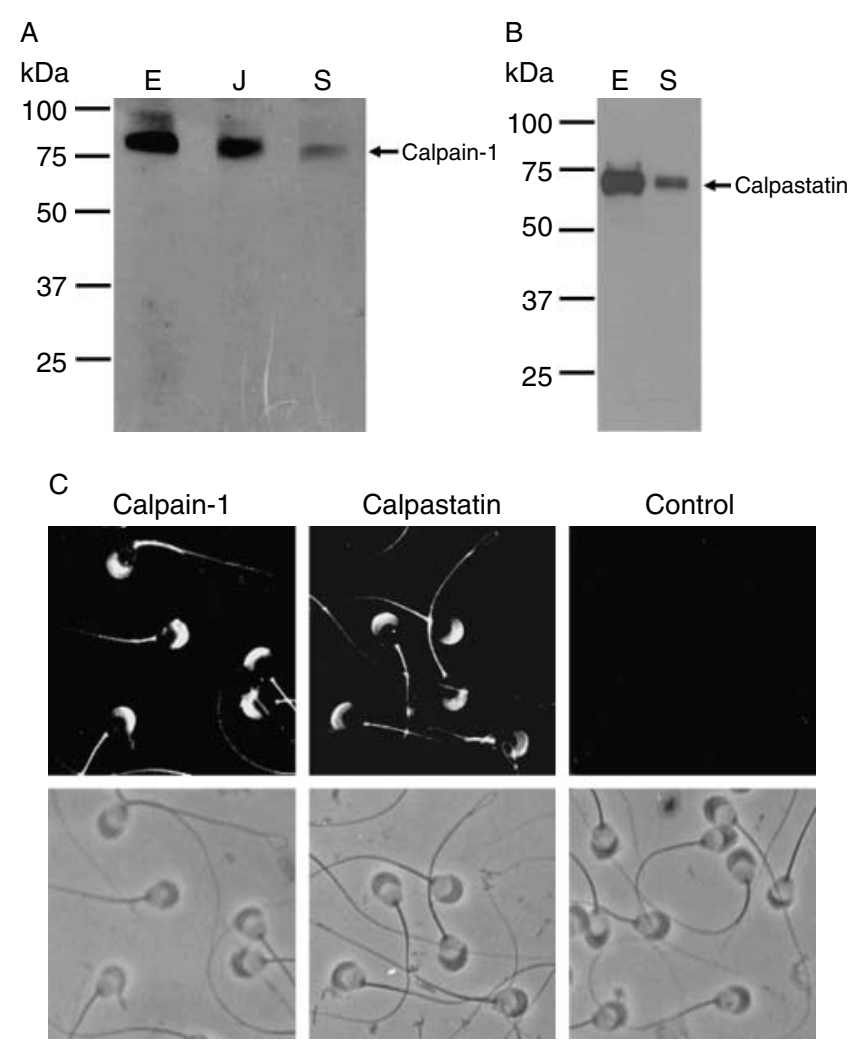

Figure 1 Calpain- 1 and calpastatin are expressed in guinea pig sperm. Calpain-1 (A) and calpastatin (B) were detected by western blot analysis using $100 \mu \mathrm{g}$ of whole sperm (S) extracts. Extracts from human erythrocytes (E) and Jurkat cells (J) were used as positive controls. (C) Formaldehyde-fixed sperm were subjected to immunofluorescence to detect the expression of calpain-1 and calpastatin. Sperm preparations subjected to immunofluorescence without addition of primary antibodies were used as controls. In addition, phase contrast micrographs are shown. Images are representative of at least three independent experiments. 
in guinea pig sperm using two different specific anticalpain-2 antibodies; however, we were unable to detect this protein using western blot or indirect immunofluorescence (Supplementary Figure 1, see section on supplementary data given at the end of this article). To confirm that anti-calpain-2 antibodies used here recognize calpain-2 from guinea pig, they were assayed in whole extracts of heart and cerebrum. Both antibodies recognized calapain-2 of guinea pig (Supplementary Figure 2, see section on supplementary data given at the end of this article). These results suggest the possibility that calpain-2 is absent in guinea pig sperm, however, is important to perform more studies to confirm this hypothesis.

\section{Calpain-1 is translocated to the PM during capacitation in a calcium-dependent manner}

The activation of calpain during normal and pathologic processes requires increases in intracellular $\mathrm{Ca}^{2+}$ and this is probably also necessary for its translocation to the PM, where several calpain target proteins are located (Hood et al. 2006). Because $\mathrm{Ca}^{2+}$ increase is one of the central intracellular events during capacitation (Coronel \& Lardy 1987, Adeoya-Osiguwa \& Fraser 1996), we decided to determine the intracellular localization of calpain-1 during capacitation. After 30 min of capacitation, we always observed a relocalization of calpain in both the apical acrosome and the postacrosomal regions
(Fig. 2A). Then, we confirmed the participation of $\mathrm{Ca}^{2+}$ in the localization changes of calpain- 1 by incubating the cells for $90 \mathrm{~min}$ in minimal culture medium containing lactate and pyruvate (MCM-PL) capacitating medium without $\mathrm{Ca}^{2+}$ (see Materials and Methods). In the absence of calcium, the distribution of calpain- 1 did not show any change, and its localization was identical to that of non-capacitated sperm (Fig. 2A). The proportion of sperm immunostained in the apical acrosome and postacrosmal regions was clearly different between sperm capacitated in complete MCM-PL and those capacitated in MCM-PL without $\mathrm{Ca}^{2+}$ (Fig. 2B). Next, we evaluated whether or not calpain-1 is translocated from the cytoplasm to the sperm membranes during capacitation; western blot of purified PM proteins showed that calpain-1 was not detected in the PM of non-capacitated sperm; however, during capacitation, calpain-1 was associated with the PM, increasing the amount associated throughout capacitation (Fig. 2C). Moreover, the translocation of calpain-1 to PM was $\mathrm{Ca}^{2+}$ dependent as shown by the absence of calpain-1 associated with the PM isolated from sperm capacitated in the absence of $\mathrm{Ca}^{2+}$ (Fig. 2C). To confirm that calpain-1 was translocated from cytosol to the PM, the presence of calpain-1 in cytosolic proteins was assayed by western blot. Using both non-capacitated and capacitated sperm in the absence of extracellular $\mathrm{Ca}^{2+}$, the amount of cytosolic calpain- 1 detected was similar to that detected in proteins from whole sperm
A

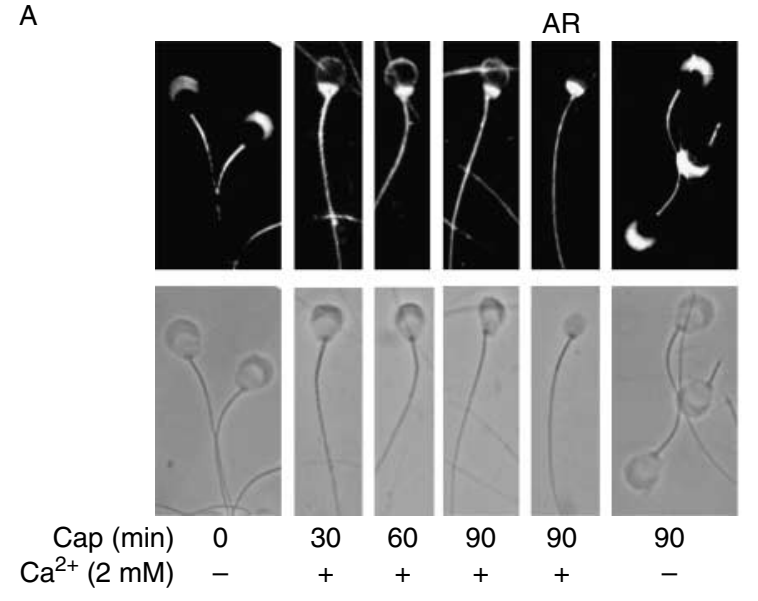

C Capacitation (min)

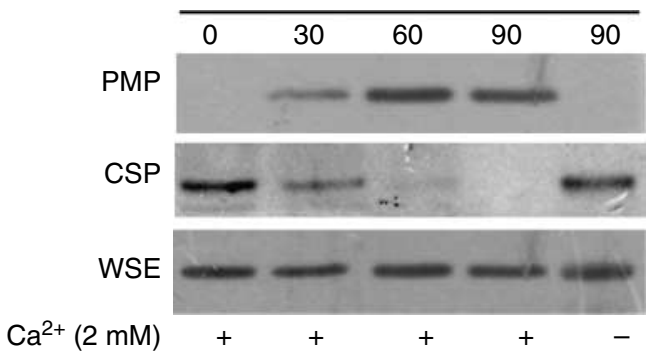

B

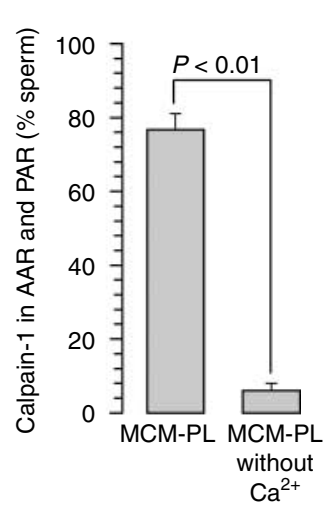

Figure 2 Calpain- 1 is translocated to plasma membrane during capacitation in a calciumdependent manner. (A) Immunolocalization of calpain-1 at indicated times during capacitation in the presence or absence of extracellular calcium; time 0 represents non-capacitated sperm and is used as reference. AR, acrosome-reacted sperm. Lower images are phase contrast micrographs of the same fields shown above. (B) Quantification of the proportion of sperm showing calpain-1 immunostaining in both the apical acrosome and postacrosomal regions after capacitation $(60 \mathrm{~min})$ in the presence or absence of calcium (mean \pm S.E.M., $n=3,250$ cells per experiment). PAR, postacrosomal region; AAR, apical acrosome region. (C) Western blot comparison of the presence of calpain-1 in plasma membranes proteins (PMP) and cytosolic proteins (CSP) of non-capacitated sperm versus capacitated sperm in the presence or absence of extracellular $\mathrm{Ca}^{2+}$. Time 0 (min) represents noncapacitated sperm. Lower panel corresponds to calpain-1 detection in whole sperm extract (WSE). Western blot shown is representative of at least three independent experiments. 
extract, while the amount of cytosolic calpain-1 in capacitated sperm underwent a decrease (Fig. 2C), which could be correlated with the increase of calpain-1 in PM (Fig. 2C). Total amount of calpain-1 did not change in non-capacitated and capacitated sperm before PM was isolated (Fig. 2C).

\section{Co-immunoprecipitation of calpain and calpastatin}

It is generally well accepted that calpastatin downregulates the activity of calpain through a direct interaction that inhibits its proteolytic activity (Melloni et al. 2006). With this in mind, we performed co-immunoprecipitation assays to evaluate the association of calpain to calpastatin during capacitation. When calpain-1 was immunoprecipitated from whole sperm extracts, calpastatin was co-immunoprecipitated (Fig. 3A). Western blot analysis of immunoprecipitates showed that calpain- 1 is interacting with calpastatin in non-capacitated sperm; moreover, such calpain-calpastatin association was found to clearly decrease with the time of capacitation (Fig. 3A and B). However, when sperm were capacitated in the absence of $\mathrm{Ca}^{2+}$, the interaction of calpain with calpastatin was similar to the non-capacitated sperm used as control (data not shown).
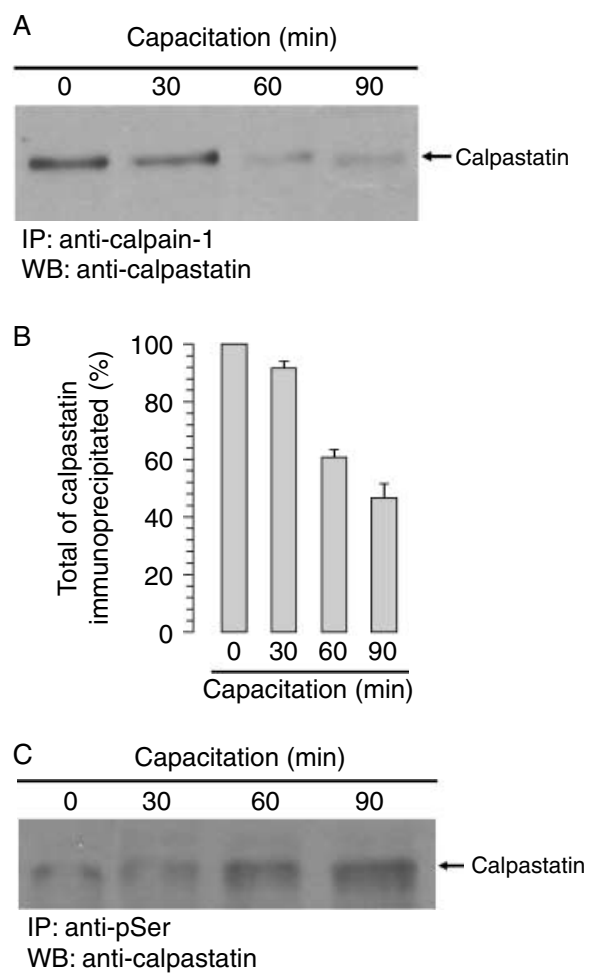

Figure 3 Calpain- 1 is associated with calpastatin. Whole sperm extracts obtained from non-capacitated and capacitated sperm at indicated times were immunoprecipitated with anti-calpain-1 (A) or antiphosphoserine (p-Ser) (C) antibodies. Immunoprecipitates were then analyzed by western blot (WB) to detect calpastatin. (B) Densitometric analysis of calpastatin co-immunoprecipitated. Blot images represent at least three independent experiments.
Because the reduction of the physical association between calpain and calpastatin is known to be mediated by serine phosphorylation of calpastatin by protein kinase C (PKC; Averna et al. 1999, Melloni et al. 2006), we decided to evaluate the calpastatin phosphorylation levels during capacitation. As can be seen in Fig. 3C, initial calpastatin phosphorylation in noncapacitated sperm was increased during capacitation and was inversely proportional to the association levels with calpain.

\section{Effect of calpain inhibitors on the AR}

Our results clearly show that calpain is active throughout the course of capacitation. In order to determine whether calpain participates on AR, we explored the effect of two calpain inhibitors; sperm were capacitated for $90 \mathrm{~min}$ in the presence of calpeptin $(0-10 \mu \mathrm{M})$ or $\mathrm{N}$-acetyl-Leu-Leu-Nle-CHO (ALLN; $0-500 \mu \mathrm{M})$, then afterwards, AR was evaluated. Both calpeptin and ALLN significantly reduced the AR in a dose-dependent manner, with a maximal inhibitory effect at 5 and $250 \mu \mathrm{M}$ respectively (Fig. 4A).

We have reported that the cytoskeleton associated with the PM is modified during capacitation (HernandezGonzalez et al. 2000). To explore the involvement of calpain in the alteration of this cytoskeleton, membraneassociated cytoskeleton from non-capacitated and capacitated sperm treated or not with calpeptin or ALLN was obtained, and then analyzed by electron microscopy. The examination of membrane cytoskeleton from non-capacitated sperm showed typical cross-linked filaments forming a dense cytoskeletal network (Fig. 4B), whereas in samples from capacitated sperm, the membrane-associated cytoskeleton exhibited empty spaces, where the cytoskeleton was not present (Fig. 4B). As expected, when sperm were capacitated in the presence of calpeptin, their cytoskeleton exposed a similar structure to samples from non-capacitated sperm (Fig. 4B). Similar results were obtained using ALLN (data not shown). Therefore, our results indicate that calpain is involved in capacitation and that its activity affects the cytoskeleton.

\section{Spectrin is cleaved by calpain-1 during capacitation}

Calpain is an important regulator of the cytoskeleton; it cleaves different cytoskeletal proteins such as the non-erythroid spectrin ( $\alpha$ and $\beta$ subunits), utrophin (Up71), and filamin-1. To determine whether the effect of calpain in the PM-associated cytoskeleton (shown in Fig. 4B) was due to cleavage of cytoskeletal proteins, we first determined the presence of these proteins in the same region where calpain- 1 is located. As shown in Fig. 5A, spectrin, Up71, and filamin-1 were located in the acrosomal region; in addition, spectrin was also 
A
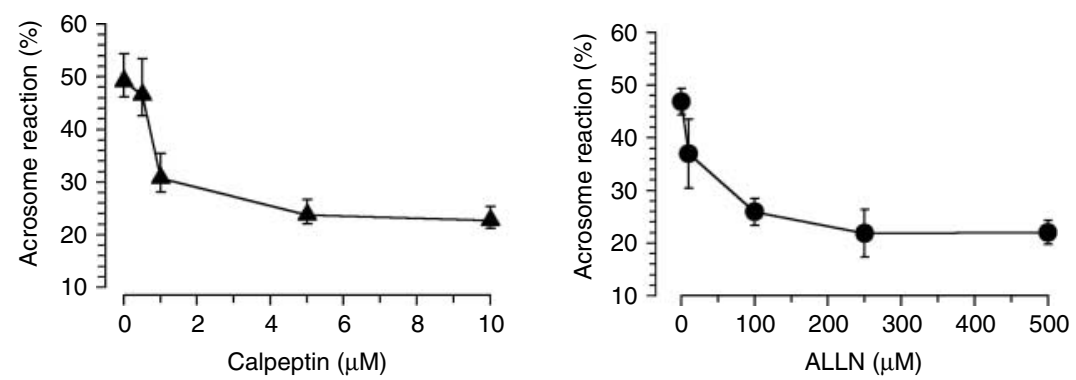

B

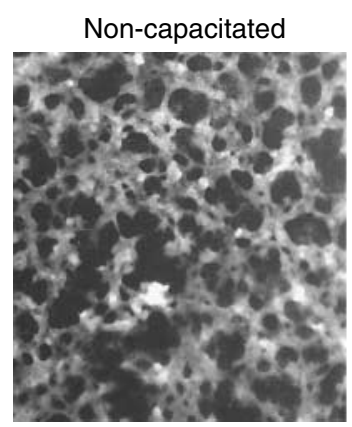

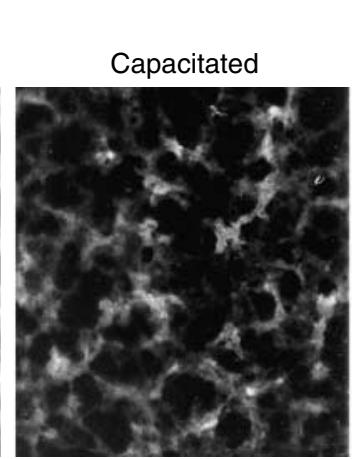

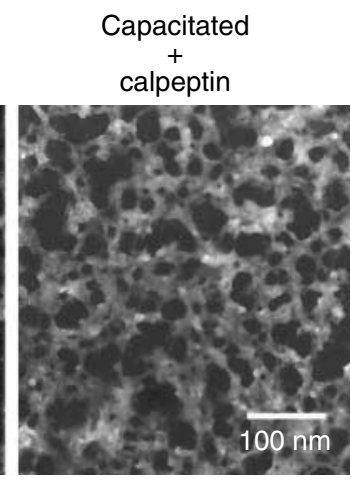

Figure 4 Calpain- 1 inhibits the acrosome reaction and alters the plasma membrane-associated cytoskeleton. (A) Sperm capacitation was performed in the presence of calpeptin or ALLN at the indicated concentrations to inhibit calpain. The graphs represent the quantification of the proportion of sperm that showed acrosome reaction (mean \pm s.E.M., $n=5,500$ cells per experiment).

(B) Inhibition of calpain-1 during capacitation prevents the alteration of the plasma membraneassociated cytoskeleton. Triton-resistant cytoskeletons obtained from plasma membranes of noncapacitated or capacitated sperm in the absence or presence of calpeptin were stained with uranyl acetate and electron microscopy micrographs taken. Images show the substructure of the plasma membrane-associated cytoskeleton. The micrographs were taken directly from negative film. located in the equatorial segment as well as in the principal piece of the flagella, whereas Up71 was found along the flagella and filamin- 1 in both the equatorial segment and middle piece (Fig. 5A). We next looked for the presence of calpain-mediated breakdown products of these cytoskeletal proteins in membranes from non-capacitated and capacitated sperm. Western blot analysis of $30 \mu \mathrm{g}$ of membrane proteins from non-capacitated sperm showed spectrin as two bands corresponding to its $\alpha(240 \mathrm{kDa})$ and $\beta(220 \mathrm{kDa})$ chains, whereas Up71 and filamin-1 were detected as bands of 72 and $280 \mathrm{kDa}$ respectively (Fig. 5B). However, when membrane proteins from capacitated sperm were analyzed, breakdown products were not detected (Fig. 5B), very likely because of the low amount of protein used. Nonetheless, when $150 \mu \mathrm{g}$ of membrane protein was used, spectrin breakdown products (SBPs) were detected in low amounts in noncapacitated sperm, whereas SBPs were greatly found in capacitated sperm. In line with previous reports, we detected two major SBPs of $\sim 150 \mathrm{kDa}$ (SBP-1) and 85 kDa (SBP-2; Fig. 6A). As expected, capacitation in the presence of calpeptin $(10 \mu \mathrm{M})$ inhibited the production of SBPs (Fig. 6A and B). Densitometric analysis of the SBPs showed that $\sim 50 \%$ of spectrin was cleaved during capacitation (Fig. 6B). On the other hand, using the same membrane samples and same conditions, we were unable to detect any breakdown products for Up71 or filamin-1 (Fig. 6C and D).

\section{Effect of calpain on the acrosome cytoskeleton}

To further explore the changes in spectrin during capacitation, we examined its localization pattern during capacitation as well as the effect of calpeptin treatment on its localization. Spectrin was always found in the principal piece of non-capacitated and capacitated sperm (Figs 5A and 7A); however, when the staining pattern of spectrin in the acrosomal region was analyzed, two differences were clearly observed: non-capacitated sperm displayed a solid uniform fluorescence pattern in the whole acrosome and throughout the equatorial segment (pattern 1 (P1)), whereas in capacitated sperm, the acrosomal staining pattern of spectrin was observed like spots with unstained spaces and the equatorial segment was not stained (pattern 2 (P2)). In all cases, acrosomes were intact as they can be observed in phase contrast micrographs (Fig. 7B). These results thus confirm the alteration undergoing by spectrin cytoskeleton during capacitation. To further determine the involvement of calpain in these changes, sperm capacitated in the presence of calpeptin $(10 \mu \mathrm{M})$ were immunostained for spectrin; we found that their acrosomal spectrin-staining pattern was similar to that of non-capacitated sperm (Fig. 7B). The quantification of the proportion of sperm showing P1 and P2 in noncapacitated versus capacitated sperm exhibited a significant difference between them, difference that was inhibited by calpeptin (Fig. 7C). The changes observed in capacitated sperm were also $\mathrm{Ca}^{2+}$ 
A
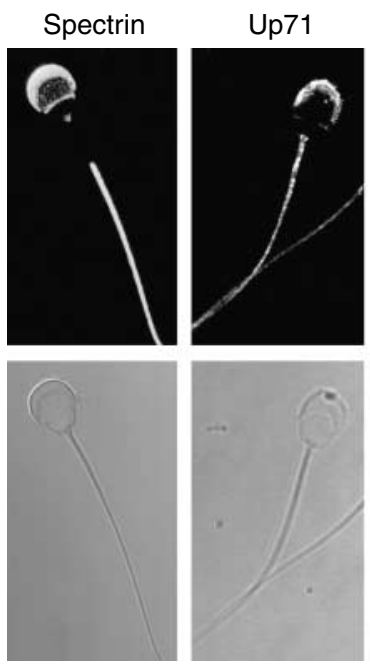

B

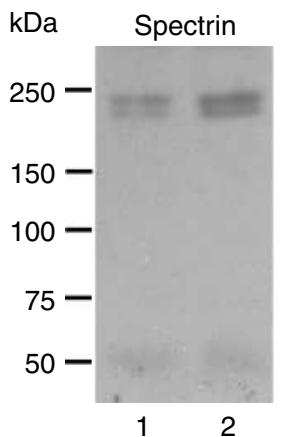

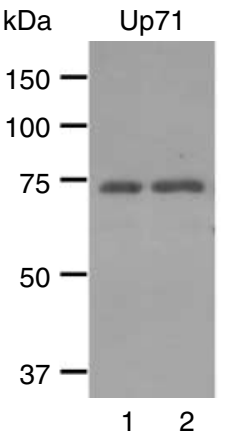

Filamin-1
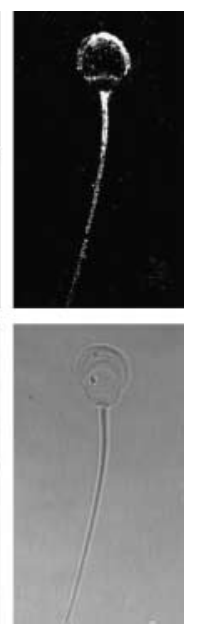

Figure 5 Localization of calpain targets in the guinea pig sperm. The expression of spectrin, Up71, and filamin-1 was determined in guinea pig sperm by immunofluorescence of formaldehyde-fixed sperm (A) as well as by western blot (B) using $30 \mu$ g of whole sperm extracts obtained from non-capacitated (1) and capacitated sperm (2). Lower images in panel (A) are phase contrast micrographs of the same fields shown above them. All proteins in panel (B) were found in the $\mathrm{Mr}$ reported for them: $240 / 220 \mathrm{kDa}$ for $\alpha / \beta$-spectrin, $70 \mathrm{kDa}$ for Up71, and $280 \mathrm{kDa}$ for filamin-1. Images shown are representative of at least three independent experiments.

dependent; sperm capacitated in the absence of $\mathrm{Ca}^{2+}$ showed a spectrin-staining pattern similar to that of noncapacitated sperm, with the sole exception that spectrin was not found in the equatorial segment (Fig. 7B).

Finally, in order to determine whether spectrin and F-actin localize to the same regions, sperm noncapacitated and capacitated in the presence or absence of calpeptin were immunostained for spectrin, while F-actin was stained using TRITC-labeled phalloidin. As we reported previously (Moreno-Fierros et al. 1992) that F-actin was located in the acrosomal region and along the flagella in both non-capacitated and capacitated sperm, and although the fluorescence intensity was not evaluated, an increase in fluorescence levels was observed in capacitated sperm when compared to non-capacitated (Fig. 7B), a phenomenon already reported in other mammalian sperm (Brener et al. 2003).

F-actin also presented a clear co-localization with spectrin in the principal piece and did not undergo any changes during capacitation (Fig. 7A). In the acrosome region, spectrin and F-actin showed a low level of co-localization in non-capacitated and capacitated sperm that was not modified by the treatment with calpeptin or by the absence of $\mathrm{Ca}^{2+}$ (Fig. 7B).

\section{Discussion}

Calpain is a cysteine protease family, where the two major and more ubiquitous members are calpain- 1 and calpain-2, which are involved in processes where the cleaving of cytoskeletal proteins is a key event. The activity of calpain is tightly regulated by cellular factors such as intracellular calcium concentration and calpastatin and very likely, by translocation to the PM. In the present study, we show for the first time evidence of the activation and regulation of calpain-1 in mammalian sperm. We also present evidence of the role of calpain in remodeling the sperm spectrin cytoskeleton, a process that can be of vital importance to achieve capacitation and AR.

The activation of calpain during both normal and pathologic processes requires an increase in $\left[\mathrm{Ca}^{2+}\right]_{i}$ as well as their translocation to the PM, where several calpain targets are located (Hood et al. 2006). Our data provide cellular and molecular evidence suggesting that calpain-1 has to undergo different changes during capacitation to become active. Previous studies and our present work demonstrate that calpain-1 and calpain-2 are located in the acrosome and in the middle piece of flagella of non-capacitated mammalian sperm (Schollmeyer 1986, Rojas et al. 1999, Yudin et al. 2000, Aoyama et al. 2001, Ozaki et al. 2001, Ben-Aharon et al. 2005). In addition, during capacitation, calpain-1 is translocated to PM and redistributed into different sperm regions; apical acrosome and postacrosmal regions (see Fig. 2A and $\mathrm{C}$ ). We can consider the noncapacitated sperm as a non-stimulated state in which $\left[\mathrm{Ca}^{2+}\right]_{i}$ is low, and although it is not known how, when sperm are incubated in a medium that allows capacitation, the $\left[\mathrm{Ca}^{2+}\right]_{\mathrm{i}}$ increase is triggered (Coronel \& Lardy 1987, Adeoya-Osiguwa \& Fraser 1996). This increase in $\left[\mathrm{Ca}^{2+}\right]_{i}$ could be linked with the translocation of calpain-1 to PM, since calpain-1 was not detected in PM from non-capacitated sperm, and both the redistribution and translocation of calpain-1 do not happen when sperm were capacitated in the absence of $\mathrm{Ca}^{2+}$.

The presence of calpastatin, the natural inhibitor of calpain, has been demonstrated in at least two sperm species: human (Rojas et al. 1999) and macaque (Yudin et al. 2000). Our results show that calpain-1 is already associated with calpastatin in non-capacitated sperm and that the interaction decreases during capacitation. Very likely, calpain-1 is kept in the sperm cytoplasm associated with calpastatin, and during capacitation, this 
A

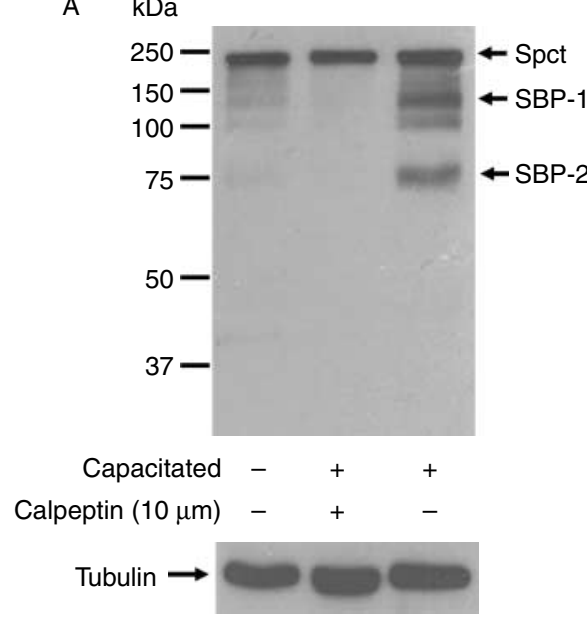

B

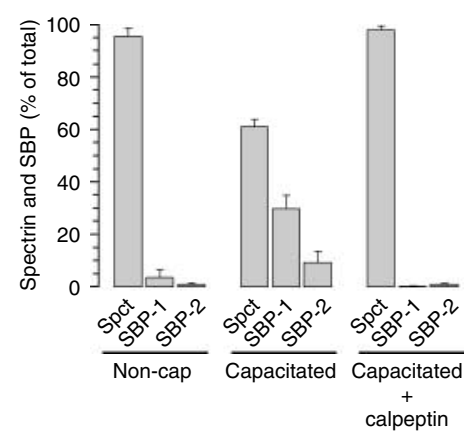

C

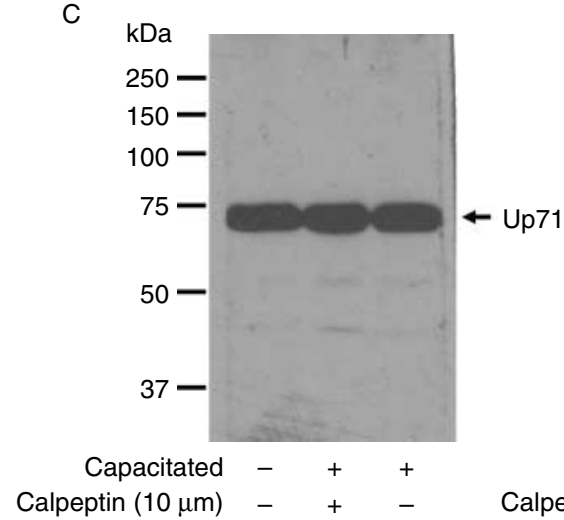

interaction is reduced allowing calpain-1 to move towards the PM. One possible mechanism to explain this reduction in interaction could involve an increase in serine phosphorylation of calpastatin, which takes place before the translocation of calpain-1 to the PM. Furthermore, it has been reported that calpastatin phosphorylation in serine residues by PKC reduces both its capacity to interact with the inactive form of calpain and its inhibitory efficiency on the active form of calpain. Moreover, calpastatin phosphorylation also increases the concentration of $\mathrm{Ca}^{2+}$ required to induce the formation of the calpain-calpastatin complex (Averna et al. 1999, Melloni et al. 2006).

In line with previous reports, our data show that AR is inhibited by calpain antagonists (Rojas et al. 1999, Aoyama et al. 2001, Ben-Aharon et al. 2005). One of the major roles of calpain in non-pathological cells is a limited cleavage of different cytoskeletal proteins in a $\mathrm{Ca}^{2+}$-dependent manner. We have previously reported that the structure of the PM-associated cytoskeleton is disturbed during capacitation (Cabello-Aguero et al. 2003), and now we add another piece of the puzzle by showing that calpain is involved in such alteration through the cleavage of spectrin. We found a clear correlation between the disruption of the spectrin cytoskeleton and AR since calpain inhibitors not only interfered with $A R$, but they also inhibited spectrin cleavage. Moreover, $\sim 50 \%$ of spectrin remained intact after capacitation, and considering that the distribution pattern of spectrin showed only alteration in the acrosome region in capacitated sperm, our results suggest that the cleavage of spectrin is a compartmentalized process. Finally, our data indicate that the activity of calpain is specific; it does not alter the actin cytoskeleton or other cytoskeletal proteins such as utrophin and filamin-1, although as in other cells, calpain might have other non-cytoskeletal substrates associated with PM such as $\mathrm{Ca}^{2+}$ channels or receptors (Sandoval et al. 2006, Croall \& Ersfeld 2007). On the other hand, although our data suggest that calpain-1 could be one of the calpains involved in spectrin cleavage and AR, we do not discard the possibility that other calpain may be implicated in such processes, since the calpain inhibitors are not specific for calpain-1, and calpain-11 has been reported in mammalian sperm (Ben-Aharon et al. 2006).

Different and important membrane domains are established in both the acrosome and flagella of mammalian sperm, which display distinct biochemical and physiological functions; however, little is known 
A

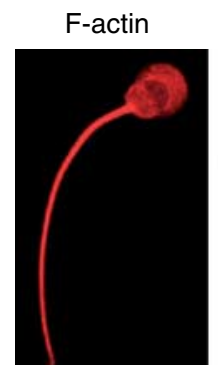

B

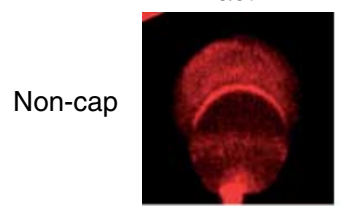

Cap

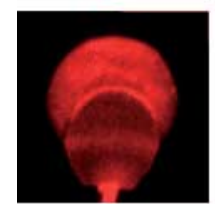

Cap $\stackrel{+}{+}$
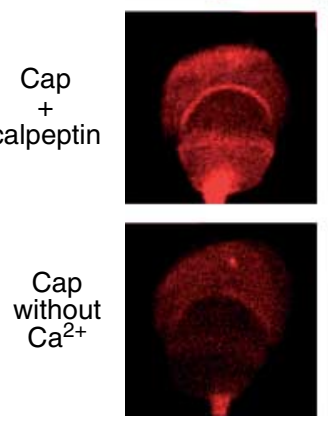

Spectrin

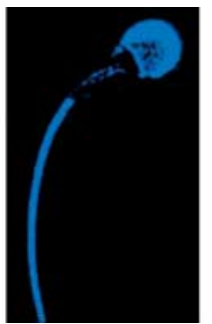

Spectrin
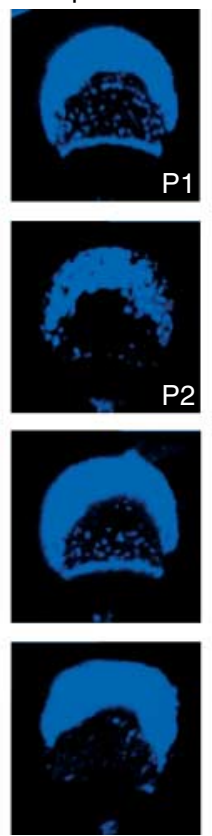

Merge

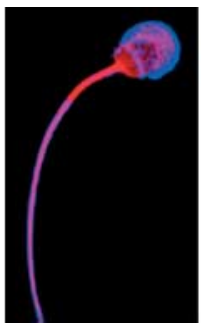

Merge
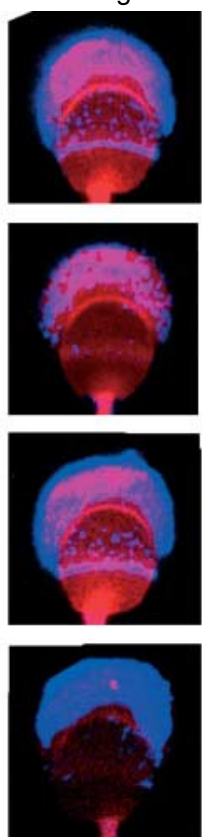

$\mathrm{PhCM}$

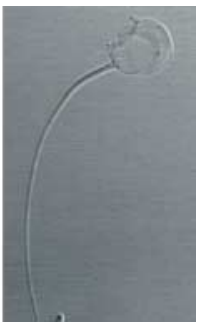

$\mathrm{PhCM}$

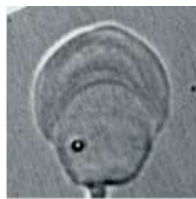

C

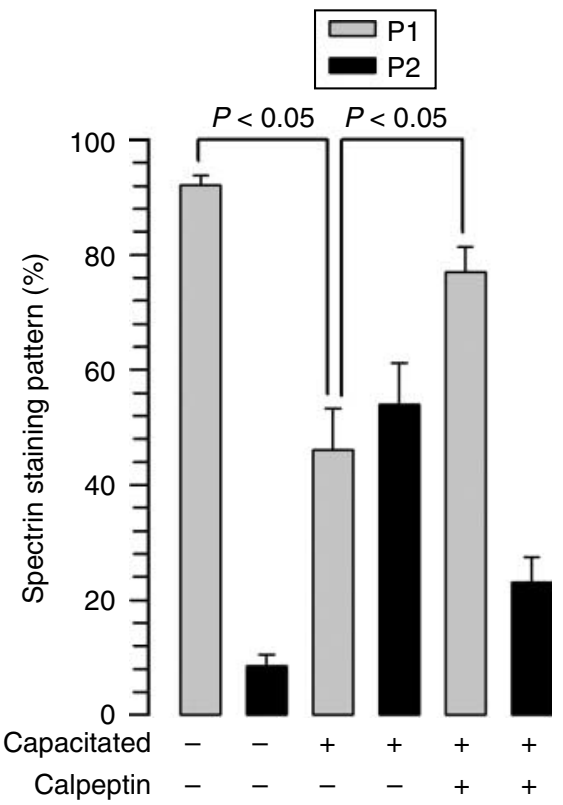

Figure 7 The staining pattern of spectrin changes in the acrosome during capacitation. The co-localization of spectrin (red) and F-actin (blue) was determined in formaldehyde-fixed non-capacitated sperm (A) and in capacitated sperm in the presence of calpeptin or in the absence of calcium (B). Confocal microscopy analysis showed two major staining patterns for spectrin that were denominated P1 (in non-capacitated sperm) and P2 (in capacitated sperm). Quantification of the proportion of sperm showing P1 and P2 is presented in (C). The graph represents means \pm S.E.M., $n=3,25$ cells per experiment. Cap, capacitated; $\mathrm{PhCM}$, phase contrast micrographs. Images shown are representative of at least three independent experiments.

about the role of the cytoskeleton in the establishment of these membrane domains. Our findings showing the localization of spectrin indicate that it could constitute and stabilize such domains, and also suggest that considering the cytoskeletal proteins associated with PM, flagella is formed by two different membrane subdomains: the middle piece, whose membrane cytoskeleton is mainly conformed by the short dystrophin Dp71/F-actin (Hernandez-Gonzalez et al. 2001), and the principal piece, whose membrane cytoskeleton is mainly conformed by spectrin/F-actin. In particular, these cytoskeletons do not undergo changes during capacitation or AR. In the same way as the principal piece, the cytoskeleton associated with PM in the acrosomal region is mainly composed of spectrin/F-actin, but with the difference that it is remodeled during capacitation. During capacitation and AR, proteins associated with PM as well as with membrane lipids compartmentalize in the acrosome region; they are redistributed inside the acrosome or distribute towards the equatorial segment and postacrosomal region as well (Rochwerger \& Cuasnicu 1992, Da Ros et al. 2004, Selvaraj et al. 2007, Tsai et al. 2007, Pasten-Hidalgo et al. 2008). These molecules in some way are maintained as compartmentalized in the acrosome before capacitation. We propose that the spectrin network works as a barrier that keeps these molecules compartmentalized. During capacitation, spectrin is severed and in consequence, its network disrupted, just then, the molecules can redistribute. Even though lipid membrane composition has been regarded as the principal mechanism to maintain and stabilize the sperm membrane domains (Boerke et al. 2008), we also consider that the spectrin cytoskeleton plays an important role to maintain these membrane domains, specially when taking into account that spectrin contains phospholipid-binding sites, through which it interact with the 
PM (Hryniewicz-Jankowska et al. 2004, An et al. 2005, Bok et al. 2007); such interaction is facilitated by cholesterol (Diakowski et al. 2006).

In conclusion, based on our findings, we propose a model in which calpain- 1 is activated during capacitation, and although its effects are visualized until AR, the activity of calpain can be of great importance for capacitation. We also propose that one of the main roles of calpain-1 during capacitation is to cleave spectrin, and as a consequence, the specific disruption of the spectrin cytoskeleton. It is important to point out that the presence of several different cytoskeletal proteins associated with PM in the mammalian sperm is already known; however, their participation in sperm physiology is unclear. In this way, our study opens the possibility to understand the role of the spectrin cytoskeleton, the signal pathways that regulate the sperm cytoskeleton, as well as its importance for capacitation and AR.

\section{Materials and Methods}

\section{Chemicals}

Sodium pyruvate, lactic acid, DL-dithiothreitol, sucrose, Triton $\mathrm{X}-100$, iodoacetamide, benzamidine, aprotinin, leupeptin, pestatin, $p$-aminobenzamidine (pAB), phenylmethyl-sulfonyl fluoride (PMSF), trizma base, ALLN, TRITC-labeled phalloidin, sodium orthovanadate, and sodium fluoride were purchased from Sigma Chemical Co. Protein A-agarose and protease inhibitors Complete cocktail tablets were purchased from Roche Diagnostics and Molecular Biochemicals. Nitrocellulose membrane, acrylamide, $N, N^{\prime}$-methylene-bis-acrylamide, and SDS were purchased from Bio-Rad Laboratories. Immobilon membrane was purchased from Millipore (Billerica, MA, USA). The antibodies mouse monoclonal anti-calpain-1 (C-266 and C-5736), monoclonal anti-calpastatin (C-270 and C-2), monoclonal anti-calpain-2 (C-268), anti-human spectrin (S-1515), and anti-chicken spectrin (S-1390) were purchased from Sigma Chemical Co.; anti-filamin-1 (H-300, sc-28284) and anti-calpain-2 (C-19, sc-7532) were obtained from Santa Cruz Biotechnology (San Jose, CA, USA); anti-utrophin 71 (Up71) was kindly donated by Dr Dominique Mornet from INSERM U-592, France; rabbit anti-phosphoserine was obtained from Zymed Laboratories Inc. (South San Francisco, CA, USA); HRP-linked goat anti-mouse IgG and TRITC-labeled goat anti-mouse IgG were purchased from Jackson Immunoresearch Laboratories Inc. (West Grove, PA, USA), whereas anti-calpeptin was obtained from Calbiochem (San Diego, CA, USA). The ECL reagent was obtained from Amersham.

\section{Animals}

All animal handling procedures and experimental design were approved by the Internal Committee for the Care and Use of the Laboratory Animal CINVESTAV-IPN (CICUAL 321-02), following the American Veterinary Medical Association guidelines. All efforts were made to minimize the potential for animal pain, stress, or distress.

\section{Capacitation in the presence and absence of ALLN or calpeptin}

Capacitation was performed as described elsewhere (CabelloAgueros et al. 2003, Pasten-Hidalgo et al. 2008); briefly, ductus deferens guinea pig sperm were obtained and washed in $154 \mathrm{mM} \mathrm{NaCl}$ solution. Sperm cells $\left(3.5 \times 10^{7} \mathrm{cell} / \mathrm{ml}\right)$ were capacitated by incubation at $37^{\circ} \mathrm{C}$ in $\mathrm{MCM}-\mathrm{PL}$ without glucose. Cells were preincubated with different concentrations of the calpain inhibitors ALLN $(0-500 \mu \mathrm{M})$ or calpeptin $(0-500 \mu \mathrm{M})$ for $15 \mathrm{~min}$ before capacitation in $154 \mathrm{mM} \mathrm{NaCl}$; cells were then centrifuged and capacitated for 60-90 min in MCM-PL in the presence of the same concentrations of ALLN or calpeptin. Immediately after capacitation, samples were fixed using $1.5 \%$ formaldehyde (final concentration) in PBS. As control, depending on the experiment, cells were incubated in $154 \mathrm{mM} \mathrm{NaCl}, \mathrm{MCM}-\mathrm{PL}$, or MCM-PL plus vehicle; in all cases, cells were incubated and fixed in parallel with treated samples (Rogers \& Yanagimachi 1975, Sanchez-Gutierrez et al. 2002).

\section{Estimation of acrosome-reacted sperm}

AR was evaluated by light microscopy based upon the presence of motile sperm without the acrosome (Yanagimachi \& Bhattacharyya 1988). Sperm were incubated in MCM-PL for 90 min (although an evaluation of AR was performed after $60 \mathrm{~min}$ of incubation), and then sperm aliquots were fixed in $1.5 \%$ formaldehyde. Quantification of AR was performed by triplicate for each experiment using a hemocytometer. To normalize the data, sperm were incubated in medium without calcium, and sperm without acrosome were quantified. Reported values represent the percentage of spermatozoa without acrosome after normalization.

\section{Immunofluorescence procedures}

Cells were fixed in $1.5 \%$ formaldehyde in PBS, permeabilized using acetone at $-20{ }^{\circ} \mathrm{C}$ for $7 \mathrm{~min}$, and washed three times in PBS and once in distilled water. Water-resuspended cells were used to prepare smears, which were air dried at room temperature and rinsed with PBS. Smears were then incubated with the primary antibody dilutes (anti-calpain 1:100, anticalpastatin 1:100, anti-filamin-1 1:100, anti-Up71 1:100, or anti-spectrin 1:250) in blocking solution (1\% BSA in PBS), under cover glass slides for $12 \mathrm{~h}$ at $4{ }^{\circ} \mathrm{C}$ in humid conditions. Exhaustive PBS washes were carried out, and then the cells were incubated for $1 \mathrm{~h}$ at $37^{\circ} \mathrm{C}$ under humid conditions with the appropriate TRITC- or Cy5-labeled secondary antibodies. In all cases, smears were exhaustively washed with PBS, and for observation, they were mounted under cover glass slides using gelvatol.

\section{F-actin detection}

The localization of F-actin cytoskeleton was revealed using TRITC-labeled phalloidin (30 $\mu \mathrm{M})$ for $45 \mathrm{~min}$ at room temperature after spectrin immunolabeling was completed. Smears were exhaustively washed with PBS and mounted as mentioned above. Images were acquired using an Olympus 
BX50 photomicroscope equipped with phase contrast and epifluorescence or using a Leica TCS SP2 confocal microscope as required.

\section{Electrophoresis and western blot}

Cells $\left(350 \times 10^{6}\right)$ were resuspended in lysis buffer $(50 \mathrm{mM}$ Tris- $\mathrm{HCl}, \mathrm{pH}$ 7.4, $1 \mathrm{mM}$ EGTA, $1 \mathrm{mM}$ PMSF, Complete, $1 \mathrm{mg} / \mathrm{ml}$ aprotinin, $10 \mathrm{mM}$ sodium orthovanadate, $25 \mathrm{mM}$ sodium fluoride, and $1 \%$ Triton X-100) as previously reported (Pasten-Hidalgo et al. 2008). Samples were then centrifuged at $5000 \mathrm{~g}$ for $5 \mathrm{~min}$ at $4{ }^{\circ} \mathrm{C}$, supernatants were collected, and protein concentration was determined (Bradford 1976). Samples were then boiled for $5 \mathrm{~min}$ in sample buffer (Laemmli 1970), and proteins were resolved in 7 or $10 \%$ SDS-PAGE and transferred onto nitrocellulose membranes (Towbin et al. 1979). Membranes were blocked using Tris-buffered saline containing $5 \%$ dried fat-free milk and $0.1 \%$ Tween-20. Membranes were then incubated overnight at $4{ }^{\circ} \mathrm{C}$ with the respective antibody (anti-calpain-1, 1:1000; anti-calpain-2, 1:1000; anti-calpastatin, 1:1000; anti-spectrin, 1:2000; antifilamin-1, 1:1000; or anti-utrophin, 1:1000). After five $7 \mathrm{~min}$ washes, membranes were incubated with the appropriated HRP-labeled secondary antibody (1:10 000). Finally, immunoreactive proteins were detected by chemiluminescence using an ECL western blot detection kit (Amersham Biosciences).

\section{Co-immunoprecipitation}

Protein extracts were incubated with $10 \mu \mathrm{l}$ of protein A-agarose and $1 \mu$ of antibody under constant agitation for $18 \mathrm{~h}$ at $4{ }^{\circ} \mathrm{C}$. Immunoprecipitates were recovered by centrifugation at $5000 \mathrm{~g}$ and washed three times with $500 \mu \mathrm{l}$ buffer A (50 mM Tris- $\mathrm{HCl}, 150 \mathrm{mM} \mathrm{NaCl}, 1 \mathrm{mM}$ EDTA, $1 \mathrm{mM}$ PMSF, $20 \mathrm{mM}$ sodium orthovanadate, $20 \mathrm{mM}$ sodium molybdate, $50 \mathrm{mM}$ sodium fluoride, Complete, and $1 \%$ Triton X-100, pH 7.5). Samples were next boiled for $5 \mathrm{~min}$ after Laemmli sample buffer was added.

\section{PM and cytosolic proteins preparation}

Cells $\left(300 \times 10^{6}\right)$ were suspended in $1 \mathrm{ml}$ buffer $B(50 \mathrm{mM}$ Tris- $\mathrm{HCl}, \mathrm{pH} 7.4,1 \mathrm{mM}$ EDTA, $1 \mathrm{mM}$ PMSF, $1 \mu \mathrm{g} / \mathrm{ml}$ soybean trypsin inhibitor, $300 \mu$ l Complete, $1 \mu \mathrm{M}$ aprotinin, $1 \mu \mathrm{M}$ pestatin, $1 \mu \mathrm{M}$ leupeptin, $10 \mu \mathrm{M}$ benzamidine, $10 \mathrm{mM}$ sodium orthovanadate, and $50 \mathrm{mM}$ sodium fluoride). Samples were sonicated for $30 \mathrm{~s}$ at $4{ }^{\circ} \mathrm{C}$ using an Ultrasonic Processor CP130PB-1 (Cole Palmer Co., Vernon Hill, IL, USA) set at amplitude of $40 \mathrm{~W}$, and then were centrifuged at $5000 \mathrm{~g}$ for $5 \mathrm{~min}$ at $4{ }^{\circ} \mathrm{C}$. Supernatants, which contained cytosolic proteins and membranes (plasma and acrosomal membranes), were recovered and centrifuged now at $100000 \mathrm{~g}$ for $2 \mathrm{~h}$ at $4{ }^{\circ} \mathrm{C}$ to separate the cytosolic proteins from membranes. Supernatants, which contained cytosolic proteins, were recovered and their protein concentration was determined. The pellets, which contained the membranes, were washed twice by centrifugation at $100000 \mathrm{~g}$ for $2 \mathrm{~h}$ at $4{ }^{\circ} \mathrm{C}$ with buffer $\mathrm{B}$ and then solubilized in buffer B containing $2 \%$ SDS. Protein concentration was determined (Markwell et al. 1978) and subjected to SDS-PAGE as described above.

\section{Isolation of sperm PMs}

PM preparations were obtained as previously described (Hernandez-Gonzalez et al. 2000); briefly, cells were resuspended in buffer $\mathrm{AH}\left(70 \mathrm{mM} \mathrm{KH} \mathrm{PO}_{4}, 90 \mathrm{mM}\right.$ sucrose, $2 \mathrm{mM} \mathrm{MgSO}_{4}, 1 \mathrm{mM}$ EDTA, $25 \mathrm{mM}$ 4-morpholineethanesulfonic acid, and $10 \mathrm{mM} \mathrm{HgCl}_{2}, \mathrm{pH}$ 6.2) containing $2 \mathrm{mM}$ $\mathrm{pAB}, 2 \mathrm{mM}$ benzamidine, $1 \mu \mathrm{M}$ leupeptin, $1 \mu \mathrm{M}$ pestatin, and $1 \mu \mathrm{M}$ aprotinin, and homogenized at $8000 \mathrm{load} / \mathrm{min}$ for $30 \mathrm{~s}$. Homogenates were centrifuged at $2000 \mathrm{~g}$ for $30 \mathrm{~min}$ (Tekmar Mark II, IKA Labortecnik, Staufen, Germany), and supernatants were collected and further processed as follows: supernatants were centrifuged at $100000 \mathrm{~g}$ for $2 \mathrm{~h}$ at $4{ }^{\circ} \mathrm{C}$; pellets containing sperm membranes obtained after centrifugation were washed twice by centrifugation with buffer $\mathrm{B}$ at $100000 \mathrm{~g}$ for $2 \mathrm{~h}$ at $4{ }^{\circ} \mathrm{C}$ and then solubilized in buffer B (50 mM Tris- $\mathrm{HCl}, 1 \mathrm{mM}$ EDTA, pH 7.4 added with $2 \%$ of SDS, $10 \mathrm{mM}$ sodium orthovanadate, and $50 \mathrm{mM}$ sodium fluoride); and protein concentration was determined (Markwell et al. 1978). Proteins from both fractions were resolved by SDS-PAGE and transferred onto nitrocellulose membranes for western blot analysis.

\section{PM-associated cytoskeleton}

PM-associated cytoskeleton was obtained as previously described (Hernandez-Gonzalez et al. 2000). Supernatants obtained after homogenization and centrifugation as in isolation of sperm PMs were fixed in 1.5\% formaldehyde in PBS for $30 \mathrm{~min}$. A drop of this membrane suspension was plated on collodion-carbon-coated grids and left to adhere for $15 \mathrm{~min}$, and aldehyde groups were blocked by incubation with $50 \mathrm{mM} \mathrm{NH}_{4} \mathrm{Cl}$ in PBS for $10 \mathrm{~min}$. Grids were then rinsed with PBS, treated with $0.2 \%$ Triton X-100, and postfixed in Karnovsky's solution for $10 \mathrm{~min}$. After three washes with PBS and twice with double-distilled water, samples were stained for $1 \mathrm{~min}$ with $0.2 \%$ of uranyl acetate in $70 \%$ ethanol, washed three times for 5 min with $70 \%$ ethanol, air dried, and examined using a JEOL 2000EX electron microscope.

\section{Statistics analysis}

All results are representative of at least three independent experiments and are expressed as average \pm s.E.M. Results comparing two samples were analyzed by paired Student's $t$-test. Significance levels were set at $P<0.05$.

\section{Supplementary data}

This is linked to the online version of the paper at http://dx.doi. org/10.1530/REP-09-0545.

\section{Declaration of interest}

The authors declare that there is no conflict of interest that could be perceived as prejudicing the impartiality of the research reported. 


\section{Funding}

This work was supported by CONACYT grant 79921 to E O Hernández-González.

\section{Acknowledgements}

We thank the staff of both Unidad de Microscopia Electrónica (UME, CINVESTAV-IPN) and Unidad de Microscopia Confocal (Dpto. Biología Celular, CINVESTAV-IPN) for providing electron microscopy and confocal facilities. We also thank Dr Alfredo Mendez for critical review of this manuscript.

\section{References}

Abou-haila A \& Tulsiani DR 2009 Signal transduction pathways that regulate sperm capacitation and the acrosome reaction. Archives of Biochemistry and Biophysics 485 72-81. (doi:10.1016/j.abb.2009.02.003)

Adeoya-Osiguwa SA \& Fraser LR 1996 Evidence for $\mathrm{Ca}(2+)$-dependent ATPase activity, stimulated by decapacitation factor and calmodulin, in mouse sperm. Molecular Reproduction and Development 44 111-120. (doi:10. 1002/(SICI)1098-2795(199605)44:1 <111::AID-MRD13 > 3.0.CO;2-7)

An X, Debnath G, Guo X, Liu S, Lux SE, Baines A, Gratzer W \& Mohandas N 2005 Identification and functional characterization of protein $4.1 \mathrm{R}$ and actin-binding sites in erythrocyte beta spectrin: regulation of the interactions by phosphatidylinositol-4,5-bisphosphate. Biochemistry 44 10681-10688. (doi:10.1021/bi047331z)

Aoyama T, Ozaki Y, Aoki K, Kunimatsu M, Tada T, Sasaki M \& Suzumori K 2001 Involvement of mu-calpain in human sperm capacitation for fertilization. American Journal of Reproductive Immunology 45 12-20. (doi:10.1111/j.8755-8920.2001.450103.x)

Averna M, De Tullio R, Salamino F, Melloni E \& Pontremoli S 1999 Phosphorylation of rat brain calpastatins by protein kinase C. FEBS Letters 450 13-16. (doi:10.1016/S0014-5793(99)00461-5)

Ben-Aharon I, Brown PR, Etkovitz N, Eddy EM \& Shalgi R 2005 The expression of calpain 1 and calpain 2 in spermatogenic cells and spermatozoa of the mouse. Reproduction 129 435-442. (doi:10.1530/ rep.1.00255)

Ben-Aharon I, Brown PR, Shalgi R \& Eddy EM 2006 Calpain 11 is unique to mouse spermatogenic cells. Molecular Reproduction and Development 73 767-773. (doi:10.1002/mrd.20466)

Bennett V \& Healy J 2008 Organizing the fluid membrane bilayer: diseases linked to spectrin and ankyrin. Trends in Molecular Medicine 14 28-36. (doi:10.1016/j.molmed.2007.11.005)

Boerke A, Tsai PS, Garcia-Gil N, Brewis IA \& Gadella BM 2008 Capacitation-dependent reorganization of microdomains in the apical sperm head plasma membrane: functional relationship with zona binding and the zona-induced acrosome reaction. Theriogenology $\mathbf{7 0}$ 1188-1196. (doi:10.1016/j.theriogenology.2008.06.021)

Bok E, Plazuk E, Hryniewicz-Jankowska A, Chorzalska A, Szmaj A, Dubielecka PM, Stebelska K, Diakowski W, Lisowski M, Langner M et al. 2007 Lipid-binding role of $\beta$ II-spectrin ankyrin-binding domain. Cell Biology International 31 1482-1494. (doi:10.1016/j.cellbi.2007.06.014)

Bradford MM 1976 A rapid and sensitive method for the quantitation of microgram quantities of protein utilizing the principle of protein-dye binding. Analytical Biochemistry 72 248-254. (doi:10.1016/00032697(76)90527-3)

Brener E, Rubinstein S, Cohen G, Shternall K, Rivlin J \& Breitbart H 2003 Remodeling of the actin cytoskeleton during mammalian sperm capacitation and acrosome reaction. Biology of Reproduction 68 837-845. (doi:10.1095/biolreprod.102.009233)

Cabello-Agueros JF, Hernandez-Gonzalez EO \& Mujica A 2003 The role of F-actin cytoskeleton-associated gelsolin in the guinea pig capacitation and acrosome reaction. Cell Motility and the Cytoskeleton 56 94-108. (doi:10.1002/cm.10135)
Camatini M, Colombo A \& Bonfanti P 1991 Identification of spectrin and calmodulin in rabbit spermiogenesis and spermatozoa. Molecular Reproduction and Development 28 62-69. (doi:10.1002/mrd. 1080280110)

Castellani-Ceresa L, Brivio MF \& Radaelli G 1992 F-actin in acrosomereacted boar spermatozoa. Molecular Reproduction and Development 33 99-107. (doi:10.1002/mrd.1080330114)

Coronel CE \& Lardy HA 1987 Characterization of $\mathrm{Ca}^{2+}$ uptake by guinea pig epididymal spermatozoa. Biology of Reproduction 37 1097-1107. (doi:10.1095/biolreprod37.5.1097)

Croall DE \& DeMartino GN 1991 Calcium-activated neutral protease (calpain) system: structure, function, and regulation. Physiological Reviews 71 813-847.

Croall DE \& Ersfeld K 2007 The calpains: modular designs and functional diversity. Genome Biology 8 218. (doi:10.1186/gb-2007-8-6-218)

Da Ros VG, Munuce MJ, Cohen DJ, Marin-Briggiler Cl, Busso D, Visconti PE \& Cuasnicu PS 2004 Bicarbonate is required for migration of sperm epididymal protein DE (CRISP-1) to the equatorial segment and expression of rat sperm fusion ability. Biology of Reproduction $\mathbf{7 0}$ 1325-1332. (doi:10.1095/biolreprod.103.022822)

Darszon A, Nishigaki T, Wood C, Trevino CL, Felix R \& Beltran C 2005 Calcium channels and $\mathrm{Ca}^{2+}$ fluctuations in sperm physiology. International Review of Cytology 243 79-172. (doi:10.1016/S00747696(05)43002-8)

Diakowski W, Ozimek L, Bielska E, Bem S, Langner M \& Sikorski AF 2006 Cholesterol affects spectrin-phospholipid interactions in a manner different from changes resulting from alterations in membrane fluidity due to fatty acyl chain composition. Biochimica et Biophysica Acta 1758 4-12. (doi:10.1016/j.bbamem.2005.11.009)

Forsman CA \& Pinto da Silva P 1989 Surface views of spermatozoa as revealed by fracture-flip. Journal of Cell Science 92 415-426.

Franco SJ \& Huttenlocher A 2005 Regulating cell migration: calpains make the cut. Journal of Cell Science 118 3829-3838. (doi:10.1242/jcs.02562)

Goll DE, Thompson VF, Li H, Wei W \& Cong J 2003 The calpain system. Physiological Reviews 83 731-801. (doi:10.1152/physrev.00029.2002)

Hernandez-Gonzalez EO, Lecona-Valera AN, Escobar-Herrera J \& Mujica A 2000 Involvement of an F-actin skeleton on the acrosome reaction in guinea pig spermatozoa. Cell Motility and the Cytoskeleton 46 43-58. (doi:10.1002/(SICI)1097-0169(200005)46:1 <43::AID-CM5 > 3.0.CO;2-1)

Hernandez-Gonzalez EO, Martinez-Rojas D, Mornet D, Rendon A \& Mujica A 2001 Comparative distribution of short dystrophin superfamily products in various guinea pig spermatozoa domains. European Journal of Cell Biology 80 792-798. (doi:10.1078/0171-9335-00202)

Hernandez-Gonzalez EO, Mornet D, Rendon A \& Martinez-Rojas D 2005 Absence of Dp71 in $\mathrm{mdx3} \mathrm{cv}$ mouse spermatozoa alters flagellar morphology and the distribution of ion channels and nNOS. Journal of Cell Science 118 137-145. (doi:10.1242/jcs.01584)

Hood JL, Brooks WH \& Roszman TL 2006 Subcellular mobility of the calpain/calpastatin network: an organelle transient. BioEssays $\mathbf{2 8}$ 850-859. (doi:10.1002/bies.20440)

Hryniewicz-Jankowska A, Bok E, Dubielecka P, Chorzalska A, Diakowski W, Jezierski A, Lisowski M \& Sikorski AF 2004 Mapping of an ankyrin-sensitive, phosphatidylethanolamine/phosphatidylcholine mono- and bi-layer binding site in erythroid beta-spectrin. Biochemical Journal 382 677-685. (doi:10.1042/BJ20040358)

Kann ML, Pradel LA \& Fouquet JP 1993 Spectrin and ankyrin like proteins in spermatids and spermatozoa of the hamster and some other mammals. Reproduction, Nutrition, Development 33 51-61. (doi:10. 1051/rnd:19930105)

Laemmli UK 1970 Cleavage of structural proteins during the assembly of the head of bacteriophage T4. Nature 227 680-685. (doi:10.1038/ 227680a0)

Lebart MC \& Benyamin Y 2006 Calpain involvement in the remodeling of cytoskeletal anchorage complexes. FEBS Journal 273 3415-3426. (doi:10.1111/j.1742-4658.2006.05350.x)

Markwell MA, Haas SM, Bieber LL \& Tolbert NE 1978 A modification of the Lowry procedure to simplify protein determination in membrane and lipoprotein samples. Analytical Biochemistry 87 206-210. (doi:10.1016/ 0003-2697(78)90586-9)

Melloni E, Averna M, Stifanese R, De Tullio R, Defranchi E, Salamino F \& Pontremoli S 2006 Association of calpastatin with inactive calpain: a 
novel mechanism to control the activation of the protease? Journal of Biological Chemistry 281 24945-24954. (doi:10.1074/jbc. M601449200)

Molinari M \& Carafoli E 1997 Calpain: a cytosolic proteinase active at the membranes. Journal of Membrane Biology 156 1-8. (doi:10.1007/ s002329900181)

Moreno-Fierros L, Hernandez EO, Salgado ZO \& Mujica A 1992 F-actin in guinea pig spermatozoa: its role in calmodulin translocation during acrosome reaction. Molecular Reproduction and Development 33 172-181. (doi:10.1002/mrd.1080330209)

Murakami T, Ueda M, Hamakubo T \& Murachi T 1988 Identification of both calpains I and II in nucleated chicken erythrocytes. Journal of Biochemistry 103 168-171.

Ozaki Y, Blomgren K, Ogasawara MS, Aoki K, Furuno T, Nakanishi M, Sasaki M \& Suzumori K 2001 Role of calpain in human sperm activated by progesterone for fertilization. Biological Chemistry 382 831-838. (doi:10.1515/BC.2001.101)

Pasten-Hidalgo K, Hernandez-Rivas R, Roa-Espitia AL, SanchezGutierrez M, Martinez-Perez F, Monrroy AO, HernandezGonzalez EO \& Mujica A 2008 Presence, processing, and localization of mouse ADAM15 during sperm maturation and the role of its disintegrin domain during sperm-egg binding. Reproduction 136 41-51. (doi:10.1530/REP-07-0300)

Pelletier R, Trifaro JM, Carbajal ME, Okawara Y \& Vitale ML 1999 Calciumdependent actin filament-severing protein scinderin levels and localization in bovine testis, epididymis, and spermatozoa. Biology of Reproduction 60 1128-1136. (doi:10.1095/biolreprod60.5.1128)

Porn-Ares MI, Samali A \& Orrenius S 1998 Cleavage of the calpain inhibitor, calpastatin, during apoptosis. Cell Death and Differentiation 5 1028-1033. (doi:10.1038/sj.cdd.4400424)

Publicover S, Harper CV \& Barratt C $2007\left[\mathrm{Ca}^{2+}\right]_{i}$ signalling in sperm making the most of what you've got. Nature Cell Biology 9 235-242. (doi:10.1038/ncb0307-235)

Rochwerger L \& Cuasnicu PS 1992 Redistribution of a rat sperm epididymal glycoprotein after in vitro and in vivo capacitation. Molecular Reproduction and Development 31 34-41. (doi:10.1002/mrd. 1080310107)

Rogers BJ \& Yanagimachi R 1975 Retardation of guinea pig sperm acrosome reaction by glucose: the possible importance of pyruvate and lactate metabolism in capacitation and the acrosome reaction. Biology of Reproduction 13 568-575. (doi:10.1095/biolreprod13.5.568)

Rojas FJ, Brush M \& Moretti-Rojas I 1999 Calpain-calpastatin: a novel, complete calcium-dependent protease system in human spermatozoa. Molecular Human Reproduction 5 520-526. (doi:10.1093/molehr/5.6.520)

Salicioni AM, Platt MD, Wertheimer EV, Arcelay E, Allaire A, Sosnik J \& Visconti PE 2007 Signalling pathways involved in sperm capacitation. Society of Reproduction and Fertility Supplement 65 245-259.

Sanchez-Gutierrez M, Contreras RG \& Mujica A 2002 Cytochalasin-D retards sperm incorporation deep into the egg cytoplasm but not membrane fusion with the egg plasma membrane. Molecular Reproduction and Development 63 518-528. (doi:10.1002/mrd.10203)
Sandoval A, Oviedo N, Tadmouri A, Avila T, De Waard M \& Felix R 2006 Two PEST-like motifs regulate $\mathrm{Ca}^{2+}$ /calpain-mediated cleavage of the CaVbeta3 subunit and provide important determinants for neuronal $\mathrm{Ca}^{2+}$ channel activity. European Journal of Neuroscience 23 2311-2320. (doi:10.1111/j.1460-9568.2006.04749.x)

Sasaki T, Yoshimura N, Kikuchi T, Hatanaka M, Kitahara A, Sakihama T \& Murachi T 1983 Similarity and dissimilarity in subunit structures of calpains I and II from various sources as demonstrated by immunological cross-reactivity. Journal of Biochemistry 94 2055-2061.

Schollmeyer JE 1986 Identification of calpain II in porcine sperm. Biology of Reproduction 34 721-731. (doi:10.1095/biolreprod34.4.721)

Selvaraj V, Buttke DE, Asano A, McElwee JL, Wolff CA, Nelson JL, Klaus AV, Hunnicutt GR \& Travis AJ 2007 GM1 dynamics as a marker for membrane changes associated with the process of capacitation in murine and bovine spermatozoa. Journal of Andrology 28 588-599. (doi:10. 2164/jandrol.106.002279)

Spungin B, Margalit I \& Breitbart H 1995 Sperm exocytosis reconstructed in a cell-free system: evidence for the involvement of phospholipase $\mathrm{C}$ and actin filaments in membrane fusion. Journal of Cell Science $\mathbf{1 0 8}$ 2525-2535.

Suarez SS 2008 Control of hyperactivation in sperm. Human Reproduction Update 14 647-657. (doi:10.1093/humupd/dmn029)

Towbin H, Staehelin T \& Gordon J 1979 Electrophoretic transfer of proteins from polyacrylamide gels to nitrocellulose sheets: procedure and some applications. PNAS 76 4350-4354. (doi:10.1073/pnas.76.9.4350)

Tsai PS, De Vries KJ, De Boer-Brouwer M, Garcia-Gil N, Van Gestel RA, Colenbrander B, Gadella BM \& Van Haeften T 2007 Syntaxin and VAMP association with lipid rafts depends on cholesterol depletion in capacitating sperm cells. Molecular Membrane Biology 24 313-324. (doi:10.1080/09687860701228692)

Virtanen I, Badley RA, Paasivuo R \& Lehto VP 1984 Distinct cytoskeletal domains revealed in sperm cells. Journal of Cell Biology 99 1083-1091. (doi:10.1083/jcb.99.3.1083)

Yagi A \& Paranko J 1995 Actin, alpha-actinin, and spectrin with specific associations with the postacrosomal and acrosomal domains of bovine spermatozoa. Anatomical Record 241 77-87. (doi:10.1002/ar.1092410111)

Yanagimachi R \& Bhattacharyya A 1988 Acrosome-reacted guinea pig spermatozoa become fusion competent in the presence of extracellular potassium ions. Journal of Experimental Zoology 248 354-360. (doi:10. 1002/jez.1402480314)

Yudin AI, Goldberg E, Robertson KR \& Overstreet JW 2000 Calpain and calpastatin are located between the plasma membrane and outer acrosomal membrane of cynomolgus macaque spermatozoa. Journal of Andrology 21 721-729.

Received 9 December 2009

First decision 20 January 2010

Revised manuscript received 8 July 2010

Accepted 17 August 2010 